\title{
Carer support: time for a rethink?
}

\author{
KENNEDY, C.
}

2019

This document is the Accepted Manuscript version of a Published Work that appeared in final form in British Journal of Community Nursing, copyright (C) MA Healthcare, after peer review and technical editing by the publisher. To access the final edited and published work see $h$ ttps://doi.org/10.12968/bjcn.2019.24.3.101. 
Carer support - time for a rethink?

A timely report by Carers UK identifies that up to 600 people a day need to leave their jobs to care for older, ill and disabled relatives (Carers UK 2019). Estimates suggest there are 5 million people balancing the demands of work and caring for older people; a 12\% increase since 2013 . Add to this the numbers of carers beyond working age and young carers, then estimates are of around 7 million carers in the UK. Three in five people in the UK will be carers at some point in their lives and by 2030 the numbers of carers will increase by 3.4 million (60\%) (Carers UK 2019). These numbers may be underestimated given the hidden nature of many caring activities particularly around the growing problems in mental health and addiction where carers may not seek help due to stigma and embarrassment.

This definition from NHS England (Accessed 11/02/19) exemplifies the breadth and scope of this role:

\section{A carer is anyone, including children and adults who looks after a family member, partner or friend who needs help because of their illness, frailty, disability, a mental health problem or an addiction and cannot cope without their support. The care they give is unpaid.}

Unpaid carers are estimated to contribute the equivalent of $f 132 \mathrm{bn}$ a year for the work they do and evidence suggests they do so at considerable personal costs to their own physical and mental health, financial security and wellbeing (Carers UK 2019).

Most district nurses would claim carer support as a key part of their work. However there exists limited research evidence as to the impact of district nursing interventions on carers and what does exist is mainly around palliative and end of life care. Care at the end of life at home is of course essential and district nurses take pride in their contributions to ensure a good death. Whilst there remains scope for improvement for care at the end of life care at home I suggest this is an area where the work of district nurses with carers is more visible.

So the question begs what about the other carers whose caring role is less clearly defined, not especially time limited and fairly invisible? Multi-morbidity, frailty and enduring mental health problems are linked to aging populations. Growing demands for support will increasingly overwhelm health and social care services. A key aim of district nursing practice is to deliver person-centred, coordinated and preventive care to reduce hospital admissions and keep people at home (Maybin et al 2016). Keeping many people at home is often wholly dependent on the carer 'managing'.

Policymakers recognise the contributions of carers although guidance varies. The Care Act (2014) bestows responsibility onto councils to promote the well-being of carers. The challenge is what this actually means and what resources district nurses can access to meet carers own needs. The Carers (Scotland) Act (2016) goes much further and is the first to set in policy the requirement for adult carers to have a 'carer support plan and a 'young carer statement' for those under 18. Enactment of this policy was from April 12018 and both health and social care providers need to prepare a local carer strategy.

Policy has to be enacted and it remains to be seen if the Carers (Scotland) Act improves carers' experiences. District nurses are in a key position to enhance carer wellbeing. Impeccable assessment is a cornerstone of district nursing practice and this needs to include an independent assessment of the carers needs. Involving the carers in joint decision making and documenting this is crucial if this largely invisible aspect of district nursing work is to be recognised. District nurses need to 
understand the changing profile of carers and the challenges they face alongside evolving demographic and societal challenges.

References

Carers UK (2019) Juggling work and unpaid care A growing issue Carers UK

NHS commissioning Who is considered a carer? NHS England https://www.england.nhs.uk>comm carers Accessed 11/02/19

Mayben J, Charles A \& M Honeyman (2016) Understanding quality in district nursing services Learning from patients, carers and staff The Kings Fund London England

Scottish Government (2016) Carers (Scotland) Act 2016 The Stationary Office UK 